\title{
In Vitro Bioassay of Purpureocillium lilacinum and Bacillus thuringiensis for Control of Meloidogyne incognita on Black Pepper (Piper nigrum L.) in Sarawak, Malaysia, Northern Borneo
}

\author{
Sui Sien LEONG ${ }^{1, *}$ \\ Stephen Chan Teck LEONG ${ }^{2}$ \\ Chen Guan PAU \\ G. Andrew C. BEATTIE ${ }^{4}$ \\ 1, 2, 3 Faculty of Agricultural Science and Forestry, Universiti Putra Malaysia \\ Campus Bintulu Sarawak, Nyabau Road, 97008 Bintulu, Sarawak, MALAYSIA \\ ${ }^{4}$ Centre for Plant and Food Science, University of Western Sydney, \\ Locked Bag 1797, Penrith, New South Wales 2751, AUSTRALIA \\ *E-mails: ${ }^{1, *}$ leongsuisien@upm.edu.my, ${ }^{2}$ dragon138leong@yahoo. \\ com, ${ }^{3}$ chenguan@gmail.com, ${ }^{4}$ A.Beattie@westernsydney.edu.au \\ ORCID IDs: ${ }^{1} 0000-0002-7050-2802,{ }^{2} 0000-0002-8838-8542,{ }^{3} 0000-0002-7654-1095$, \\ ${ }^{4} 0000-0002-4667-9704$
}

\begin{abstract}
This study aimed to evaluate strains of the entomopathogenic fungus Purpureocillium lilacinum and the bacterium Bacillus thuringiensis from Bintulu, in north-eastern Sarawak, Malaysia for their in vitro nematicidal properties against different developmental stages of Meloidogyne incognita. Ten indigenous novel strains of $P$. lilacinum, a commercial strain of the fungus ( $P$. lilacinum $\mathrm{M})$, and a strain of $B$. thuringiensis carrying Cry6 and Cry 14 gene sequences were screened for parasitism against $M$. incognita females and eggs, egg hatching inhabitation and $2^{\text {nd }}$ stage of active juveniles (J2) mortality. Our study demonstrates that $P$. lilacinum $\mathrm{A}$ and $P$. lilacinum $\mathrm{B}$ were the most effective biocontrol agent against M.incognita females, eggs and $\mathrm{J} 2$ due to highest infection of females, eggs and significant decrease in egg hatching events. P. lilacinum A, P. lilacinum $\mathrm{B}$, and $P$. lilacinum $\mathrm{M}$ (positive control) demonstrated highly significant infection $(>90 \%, P \leq 0.01)$ on $M$.incognita female nematodes. The present study revealed that spore suspension $\left(10^{5} \mathrm{spore} / \mathrm{mL}\right)$ of $P$. lilacinum A, $P$. lilacinum B and $P$. lilacinum $\mathrm{M}$ resulted in $78.8 \%$, $66.0 \%$ and $73.4 \%$ parasitism on eggs, respectively. $P$. lilacinum A, P. lilacinum B and $P$. lilacinum $\mathrm{M}$ with low mortality of $6.0 \%, 5.5 \%$ and $5.7 \%$, respectively, showed significant $(P<0.05)$ differences in mortality effect on J2 of M.incognita as compared with control treatment $(2.3 \%)$. Hatching of $M$. incognita eggs incubated in spore suspension of $P$. lilacinum $\mathrm{A}, P$. lilacinum $\mathrm{B}$ and $P$. lilacinum $\mathrm{M}$ for seven days were reduced by $89 \%$ when corrected for control mortality $(26 \%)$.
\end{abstract}

Key words: Laboratory bioassay, Meloidogyne incognita, Purpureocillium lilacinum, Bacillus thuringiensis, biocontrol, root-knot nematodes

Leong, S.S., Leong, S.C.T., Pau, C.G., \& Beattie, G.A.C. (2021). In vitro bioassay of Purpureocillium lilacinum and Bacillus thuringiensis for control of Meloidogyne incognita on black pepper (Piper nigrum L.) in Sarawak, Malaysia, Northern Borneo. Journal of the Entomological Research Society, 23(1), 41-59. 


\section{INTRODUCTION}

Black pepper (Piper nigrum L.) (Piperales: Piperaceae), the king of spices, is an important cash crops supporting the livelihood of about 67,000 rural dwellers in upland areas of Sarawak, Malaysia in northern Borneo. Such areas are loosely defined as generally remote, interior, hilly to mountainous landscapes and tablelands at moderate to high elevations where dryland farming is dominant (Li, 1999). Sarawak has the right latitude, sufficient level of rainfall, and suitable soil profile and topography for planting quality pepper. The black pepper industry is the largest agricultural export commodity of Sarawak, with production area of approximately 16,021 hectares producing 34,294 tonnes of peppercorn (MPIC, 2013). Annual export income was valued at RM 1.95 billion or USD 0.48 billion in 2019. Piper nigrum is attacked by several pests and diseases (Kueh,1986), the most economically important of which in Sarawak are root-knot nematodes (RKN), Meloidogyne spp. (Heteroderidae), that threaten the viability and sustainability of the black pepper industry (Kueh \& Teo, 1978; 1990; Leong, 1986; Kueh \& Sim, 1992; Ramana \& Eapen, 2000; Eng, 2001).

In the absence of effective control of RKN, badly infested vines are stunted with some yellowing and gall formation on the roots. Vines subsequently become unproductive and are abandoned, resulting in substantial economic losses to pepper farmers. Currently, no RKN resistant black pepper cultivar is available in Sarawak (Eng, 2001) and nematicides are usually expensive and may raise problems of environmental pollution and/or of accumulation of toxic residues in edible plant products. They also require frequent application to be effective against nematodes (Gowen,1997). On the other hand, microbial control agents (MCAs) are gaining popularity in integrated nematode management programs due to promising results of their use and relative safety with respect to synthetic nematicides (Mukhtar \& Pervaz, 2003; Dong \& Zhang, 2006).

Purpureocillium lilacinum ((Thom) Luangsaard et al (2011)) (Ophiocordycipitaceae), a saprophytic soil fungus known as a natural facultative egg parasite of root-knot and cyst nematodes (Kannan \& Veeravel, 2012) has gained attention of the researchers over the past decade due to its efficacy as a parasite for suppressing populations of phytophagous nematodes (Jatala, 1986; Dube \& Smart, 1987; Freitas, Ferraz, \& Muchovej, 1995; Khan et al, 2006a; Kiewnick \& Sikora, 2006; Oclarit \& Cumagun, 2009; Brand, Soccol, Sabu, \& Roussos, 2010; Kannan \& Veeravel, 2012; Timper, 2014). It was reported with high frequency of occurrence in the tropics and subtropics (Morgan-Jones, White, \& Rodriguez-Kabana, 1984; Akyazi \& Dickson, 2014) and can be found in most of agricultural soils (Brand et al., 2010). Eng (2001) reported that $82.9 \%$ of 43 surveyed farms in Sarawak contained P. lilacinum despite intensive application of nematicides in the farms. Cabanillas et al. (1989) observed maximum growth of $P$. lilacinum at temperature ranged from $24^{\circ} \mathrm{C}-30^{\circ} \mathrm{C}$. They reported that $P$. lilacinum was able to grow on a wide range of common organic substrates and remain competitive with other microbes in the soil. It also tolerated broad range of soil $\mathrm{pH}$ and was able to grow well at $15^{\circ}-30^{\circ} \mathrm{C}$. Since $P$. lilacinum has high adaptability in its life strategy, it is competitive in a broad spectrum of range adaptability. 
In Vitro Bioassay of P. lilacinum and B. thuringiensis for Control of M. incognita

Bacillus thuringiensis (Bt) Berliner (Bacillaceae), a well-known entomopathogenic bacterium used for the control of insects for more than four decades, (Brar, Verma, Tyagi, Valéro, \& Surampalli, 2006) has also drawn intensive studies on its nematicidal effects against economically important phytophagous nematodes (Devidas \& Rehberger, 1992; Siddiqui \& Mahmood, 1994; Carneiro, Souza, \& Belarmino, 1998; Mozgovaya, Byzov, Ryabchenko, Romanenko, \& Zvyagintsev, 2002; El-Nagdi \& Youssef, 2004; Mohammed et al, 2008; Khan et al, 2010). Carneiro et al (1998) claimed that $B$. thuringiensis was efficacious in killing freshly hatched $2^{\text {nd }}$ stage juveniles (J2) of sugarcane eelworm, Meloidogyne javanica (Treub,1885) Chitwood, 1949. Mozgovaya et al (2002) reported $80 \%$ mortality of nematodes after in vitro treatment with B. thuringiensis. El-Nagdi \& Youssef (2004) found that soaking faba beans with $B$. thuringiensis reduced the population density of $M$. incognita and increased the plant growth. According to Osman, Ameen, Mohamed, El-Mohamedy, \& Elkelany (2018), B. thuringiensis applied alone improved the growth parameters of eggplant and reduced nematode development. Mohammed et al (2008) reported that the spore/crystal proteins of $B$. thuringiensis showed high nematicidal activity against $M$. incognita (Kofoid and White) Chitwood. However, no current report was found on the positive effect of $B$. thuringiensis in controlling RKN development in black pepper. Therefore, studies were conducted to investigate the feasibility for use of $P$. lilacinum and $B$. thuringiensis as alternatives to the chemical nematicides currently used to control RKN in black pepper. The objective of this study was to evaluate the local virulent strains of $P$. lilacinum and $B$. thuringiensis for their in vitro nematicidal properties against different developmental stages of $M$. incognita in the laboratory bioassay.

\section{MATERIAL AND METHODS}

\section{Establishment of pure Meloidogyne incognita (MI) culture}

A pure population of $M$. incognita was established on a local variety of tomato (Solanum lycopersicum L. (Solanales: Solanaceae) from a single egg mass of $M$. incognita, and maintained on tomato plants raised in pots filled with sterilized pot mixture (2: 1: 1 sand, loam, cocoa peat, respectively).

\section{Isolation, screening, and identification of Purpureocillium lilacinum (PL)}

Seven indigenous strains of $P$. lilacinum, designed as $P$. lilacinum A, $P$. lilacinum EJ1, $P$. lilacinum EJ2, $P$. lilacinum EK1, $P$. lilacinum EK2, $P$. lilacinum EK3, and $P$. lilacinum EK4 were isolated from egg masses and females of M.incognita while three indigenous strains, designed as $P$. lilacinum $1 \mathrm{~A}, P$. lilacinum $\mathrm{B}$ and $P$. lilacinum $\mathrm{SA}$ were obtained from soil. $P$. lilacinum $\mathrm{A}, P$. lilacinum $\mathrm{B}$ and $P$. lilacinum $\mathrm{M}$ were further confirmed at molecular level with primer pairs: ITS1-ITS4 (Inglis \& Tigano, 2006) and EF4-EF3 (Glass \& Donaldson, 1995) before being assessed for their in vitro antagonism on egg masses, eggs, egg hatch and $2^{\text {nd }}$ stage of juveniles $(\mathrm{J} 2)$ of $M$. incognita. The sequences for ITSI, ITS4 and EF3, EF4 genes were listed as follows: 
LEONG, S.S., LEONG, S.C.T., PAU, C.G., BEATTIE, G.A.C.

ITS1 (5'-TCC GTA GGT GAA CCT GCG G-3'),

ITS4 (5'-TCC TCC GCT TAT TGA TAT GC-3') and

EF3 (5'-TCCTCTAAATGACCAAGTTTG-3'),

EF4 (5'-GGAAGGG[G/A]TGTATTTATTAG-3').

Identification of $P$. lilacinum was based on classical (morphological and morphometric properties) and molecular methods (Luangsa-Ard et al, 2011). P. lilacinum M, a commercial strain (SUBOTANI, Malaysia) served as positive control in all tests. Roots and rhizosphere soils around black pepper roots were collected from several areas in two black pepper farms, one at Bintulu $\left(3.2167^{\circ} \mathrm{N}, 113.0989^{\circ} \mathrm{E}\right)$ in north-eastern Sarawak and the other at Kuching $\left(1.4497^{\circ} \mathrm{N}, 110.1339^{\circ} \mathrm{E}\right)$ in the south-eastern Sarawak, where RKN disease is prevalent. Root pieces were washed in gentle running tap water for $5 \mathrm{~min}$. Females and egg masses were extracted from roots using method described by Sun, Gao, Shi, Li, \& Liu (2006) before transferred to $\mathrm{PDA}+[$ Potato Dextrose Agar (Merck, Darmstadt, Germany) amended with $0.01 \%(\mathrm{w} / \mathrm{w})$ chloramphenicol (Sigma, USA) and 3\% (w/w) sodium chloride] plate. To isolate from soil: Serial dilution and a standard pour plate technique were used (Thomas, Sekhar, Upreti, Mujawar, \& Pasha, 2015). Dilution at $10^{-1}, 10^{-2}$ and $10^{-3}$, were subsequently spread onto PDA+ plates and incubated at room temperature $\left(28^{\circ} \pm 1^{\circ} \mathrm{C}\right)$ for 7 days.

Determination of the effect of $P$. lilacinum on female nematodes of $M$. incognita

$P$. lilacinum A, P. lilacinum EJ1, P. lilacinum EJ2, P. lilacinum EK1, P. lilacinum EK2, $P$. lilacinum EK3, P. lilacinum EK4, $P$. lilacinum $1 \mathrm{~A}, P$. lilacinum $\mathrm{B}, P$. lilacinum SA and $P$. lilacinum $M$ were preliminarily screened for their efficacies in infecting $M$.incognita female nematodes. Five female nematodes of approximately equal size (from pure culture) were surface-sterilized with $1.0 \%$ sodium hypochlorite for 5 minutes after extracted from tomato roots. These were later collected on a $200-\mu \mathrm{m}$ sieve and were rinsed 3 times with chlorine-free sterile tap water (Sun et al., 2006) before placing at the edge of 5-day-old fungal colony grown on water agar $2.0 \%(\mathrm{w} / \mathrm{w})$. Plates were arranged according to a Simple Randomized Design (SRD), run in four replicates and incubated at room temperature $\left(28^{\circ} \pm 2{ }^{\circ} \mathrm{C}\right)$. After 4 days, females were observed under stereo microscope (45x) to detect emerging mycelium from the body surface as sign of colonization.

\section{P. lilacinum (PL) infection rate on females and egg masses of M.incognita}

Infection rate on M.incognita females by selected P. lilacinum was conducted with ten females per plate and four replications per fungus treatment. Sign of colonization was observed daily until the $6^{\text {th }}$ day. Similarly, the procedure was repeated for egg masses.

\section{Infection on eggs of $\boldsymbol{M}$. incognita}

M.incognita egg suspensions were prepared as described by Nitao, Meyer, \& Chitwood (1999). Fifty (50) $\mu \mathrm{L}$ freshly prepared egg suspensions (approximately 300 fresh eggs) was pipetted separately into sterile McCartney bottles and to which 
In Vitro Bioassay of P. lilacinum and B. thuringiensis for Control of M. incognita

$1 \mathrm{~mL}$ of fungus spore suspension $\left(10^{5}\right.$ spores $\left./ \mathrm{mL}\right)$ prepared in sterile distilled water was added. Sterile water was added for control treatment. The entire procedure was conducted in aseptic condition. Bottles were sealed with Parafilm (Sigma, USA), arranged in a CRD and placed in the dark at room temperature $\left(28^{\circ} \pm 2^{\circ} \mathrm{C}\right)$ with four replications per fungus treatment. Four days later, drops of egg suspension from each replicate (approximately 100 eggs) were pipetted onto glass slides, stained with lactophenol cotton blue and examined under a compound microscope $(\times 400)$ for signs of parasitism.

\section{Impacts of spore suspension of $P$. lilacinum on egg hatch and $2^{\text {nd }}$ stage juveniles (J2) of $M$. incognita}

Procedures described for egg parasitism test were repeated with fresh material but the incubation period was extended to seven days. Egg hatch rate and juvenile stage 2 (J2) mortality were determined by counting all eggs, J2 and dead J2 in a counting disc under a stereo-microscope, which were later calculated to determine the percentage of egg hatch and percentage of $\mathrm{J} 2$ mortality according to the following formula:

Egg hatch percentage $=100 \times \mathrm{J} 2 /($ eggs $+\mathrm{J} 2)$

$\mathrm{J} 2$ mortality percentage $=100 \times$ dead J2/total J2,

A piece of eyelash attached to a tooth- pick was used to probe the tail of $\mathrm{J} 2$. They were considered dead if they became rigid and did not react when probed by the eyelash.

\section{Isolation of Bacillus thuringiensis (Bt)}

Soil samples were randomly collected from several locations of a cattle farm at the University Putra Malaysia (UPM) Bintulu Sarawak Campus $\left(3.2058^{\circ} \mathrm{N}, 113.0999^{\circ} \mathrm{E}\right)$. Sodium acetate- $(0.25 \mathrm{M})$-selection heat-pasteurization, and $50 \%$ ethanol treatment methods were used for $B$. thuringiensis isolation as described by Xavier, Reena Josephine, \& Sreeramanan (2007). B. thuringiensis colonies were selected based on $B$. thuringiensis colony morphology, with the appearance of a fried egg on the plates (Barathi, Sangeetha, Karthick, Govindaraju, \& Indra Arulselvi, 2012). B. thuringiensis was again inoculated in nutrient broth medium for sporulation. The culture was further examined and confirmed under phase contrast microscope.

The production of parasporal crystal (a solid crystalline protein which is produced next to the endospore during spore formation of $B$. thuringiensis) in $B$. thuringiensis culture was detected by adopting crystal protein staining method of Sharif \& Alaeddinoğlu (1998). Smear of 2-day-old culture of $B$. thuringiensis prepared on a glass slide was dipped in a Coomassie brilliant blue solution $(0.25 \%$ Coomassie brilliant blue, $50 \%$ ethanol and $7 \%$ acetic acid) for 3 minutes, then washed with tap water, dried and observed under a light compound microscope at $1000 x$ magnificent without cover and oil immersion. 


\section{Detection of Cry Gene with Molecular Method and forward}

DNA of an overnight $B$. thuringiensis culture was extracted according to DNA extraction procedure for $P$. lilacinum except incubation of pellet in $180 \mu \mathrm{L}$ of TE buffer at $100^{\circ} \mathrm{C}$ for 10 minutes was omitted. Forward and backward primers of Cry 6 and Cry 14 (Salehi Jouzani et al, 2008) were performed, replacing ITS and EF primers, in order to detect nematode-specific Cry active genes, Cry6 and Cry14. The sequences for Cry6 and Cry14 genes were as follows: Cry6+F (5'-TGG CGT AGA GGC TGT TCA AGT A-3'), Cry6-R (5'-TGT CGA GTT CAT CAT TAG CAG TGT-3') and Cry14+F (5'-ATA ATG CGC GAC CTA CTG TTG T-3'), Cry14-F (5'-TGC CGT TAT CGC CGT TAT T-3').

\section{Bioassay on the toxicity of $B$. thuringiensis parasporal crystal on $2^{\text {nd }}$ stage juveniles (J2) of $M$. incognita}

A bioassay method developed by Zi-Quan et al (2008) was modified and used for testing the parasporal crystal protein of $B$. thuringiensis against $M$. incognita. $B$. thuringiensis isolate that carry Cry active genes (Cry6 and Cry14) was selected for this study and named as $B$. thuringiensis Bt 614 . The presence of Cry6 and Cry14 genes in $B$. thuringiensis served as an indication for the production of parasporal crystal 6 and crystal 14 , which can be toxic and show activity against root-knot nematodes. The selected $B$. thuringiensis 614 initially was grown in nutrient broth on a rotary shaker (180 rotations per minute) for 2 days at $32^{\circ} \mathrm{C}$ in order to reach stationary phase with cell density of (1-5) $\times 10^{9} \mathrm{CFU} / \mathrm{mL}$ (Mozgovoya et al, 2002). B. thuringiensis broth culture was subjected to centrifugation at $12,000 \mathrm{~g}$ for 20 minutes for precipitation of cells, spores and crystals (Carneiro et al, 1998). The precipitates were washed two times in chilled distilled water by centrifugation before re-suspended in sterile distilled water to the initial volume.

A suspension ( $\left.1.85 \times 10^{4} \mathrm{CFUs}\right)$ of $B$. thuringiensis spore, crystals and cells were two-fold serially diluted to achieve concentrations of $50 \%, 25 \%, 12.5 \%$ and $6.25 \%$. Two $\mathrm{mL}$ of each concentration was added to $3 \mathrm{~mm}$ diameter glass dish. Two $\mathrm{mL}$ of $\mathrm{J} 2$ M. incognita suspension (average $62 \mathrm{M}$. incognita juveniles $/ \mathrm{mL}$ ) was later added into each dish. Glass dish containing $2 \mathrm{~mL}$ of sterile tap water and $2 \mathrm{~mL}$ of $\mathrm{J} 2$ suspension served as control. There were four replications for each treatment, run in a CRD. After 24, 48 and 77 hours of incubation periods, each dish was stirred for 30 seconds to mix the content before placed under a dissecting microscope to determine the number of paralyzed $\mathrm{J} 2$ from a total count of 50 nematodes. Mean percentage of paralyzed $\mathrm{J} 2$ was estimated.

\section{Statistical analysis}

Means of data in percentage subjected to arc-sine transformation, were analysed according to standard procedure for analysis of variance (ANOVA). Differences between means were compared using SAS version 9.0 for significance according to Duncan multiple range test $(\mathrm{P}<0.01$ and $\mathrm{P}<0.05)$. Untransformed arithmetic means are reported. 
In Vitro Bioassay of P. lilacinum and B. thuringiensis for Control of M. incognita

\section{RESULTS AND DISCUSSION}

\section{Determination of the impact of $P$. lilacinum on female nematodes of $M$. incognita}

Fig. 1 showed that infection of $M$. incognita females by all $P$. lilacinum isolates differed according to the isolate, with isolate $P$. lilacinum Ek2, P. lilacinum Ek4 and P. lilacinum EJ2 causing lower infection levels and $P$. lilacinum $1 \mathrm{~A}, P$. lilacinum EK1, P. lilacinum EK3 in moderate infection levels while $P$. lilacinum $\mathrm{A}, P$. lilacinum $\mathrm{M}, P$. lilacinum $\mathrm{B}, P$. lilacinum EJ1 and $P$. lilacinum SA resulting in highly significant $(P<0.0001)$ infection levels (>80\%). Similar results were reported by Eapen, Beena, \& Ramana (2005) on the significant infection of $P$. lilacinum isolate on $M$. incognita females. A stereo microscope (40x) observation demonstrated radiating mycelia from the female's body (Fig. 2a and b) unrestricted to vulva, anus or broken opening, which corroborates that appressoria are not involved in the penetrating process due to the lack of a tough cross-linked chitin layer on the female body as described in early studies (Morgan-Jones et al,1984; Holland, Williams, \& Khan, 1999; Khan et al,2006b). However, according to Jatala (1986), Peruvian isolate of $P$. lilacinum infected the female of $M$. javanica (Treub) only by body opening. Khan et al (2006b) suggested that this penetrating process may be attributed to different profile enzymes of each strain that help in the direct cuticle penetration.

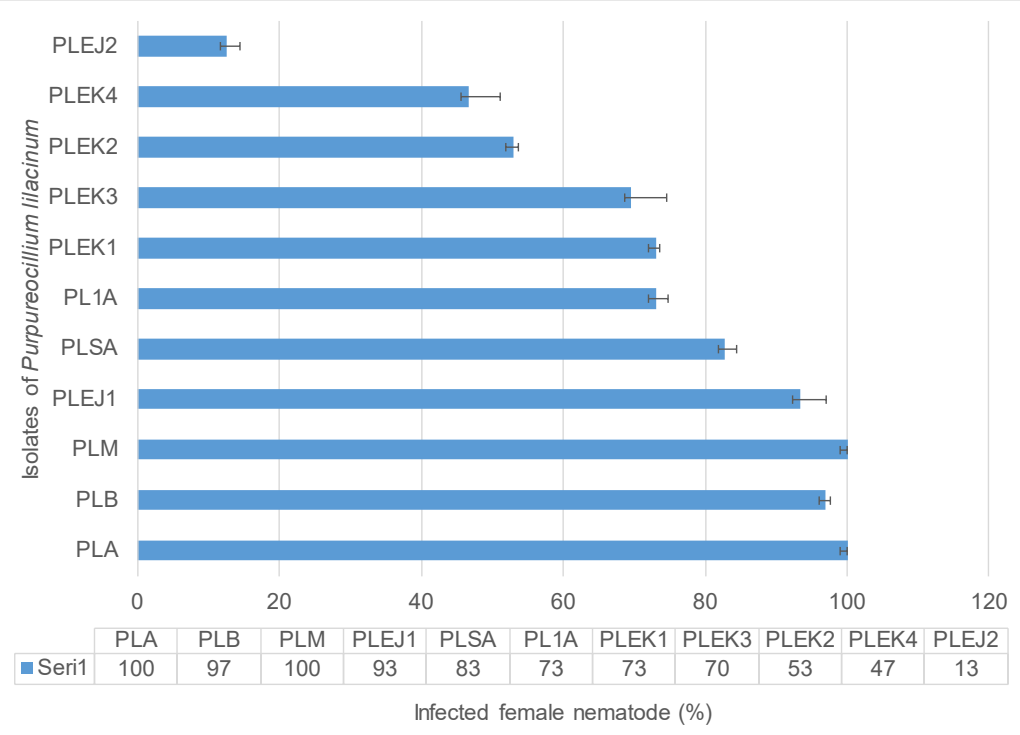

Fig. 1 Percentage of female Meloidogyne incognita infection by Purpureocillium lilacinum, determined by observing emerging hyphae from the body surface after 4 days of incubation under a stereo microscope at $40 \times$. Value represents mean (\%) of five replications. Means followed by the same letter are not significantly different according to Duncan Multiple Range Test at $P<0.01$. Vertical bars indicate standard error of the means. 
LEONG, S.S., LEONG, S.C.T., PAU, C.G., BEATTIE, G.A.C.

\section{$P$. lilacinum infection rate on females and egg masses of $\boldsymbol{M}$. incognita}

Fig. 2a demonstrated higher rates of infection on $M$. incognita females by isolates $P$. lilacinum A, P. lilacinum B and P. lilacinum M. Both P. lilacinum A and P. lilacinum $\mathrm{M}$ on the $1^{\text {st }}$ day reached $50 \%$ infection rate followed by $P$. lilacinum $B$ with a rate of $10 \%$. Nevertheless, all isolates eventually achieved $100 \%$ infection on the $6^{\text {th }}$ day. It was observed that from the $3^{\text {rd }}$ day onwards, there was no significant increase in percentage of infection on female nematodes by the three above isolates.
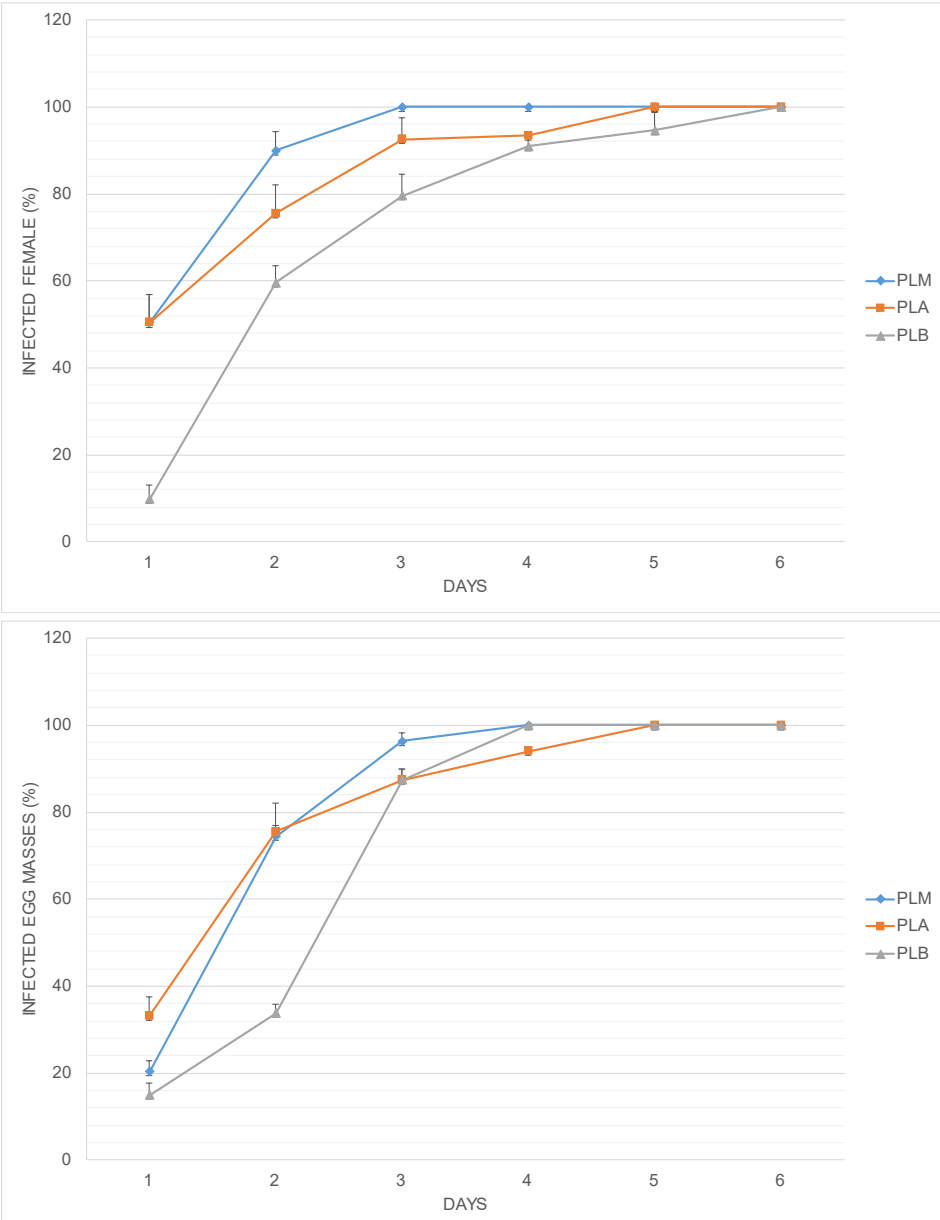

Fig. 2 Infection rate of Purpureocillium lilacinum on Meloidogyne incognita (a) infected female nematodes and (b) infected egg masses under in vitro condition. Sign of infection by observing the emerging hyphae from the surface of specimens (female or egg mass). Each value represents the mean [a \% of infected female; $b \%$ of infected egg masses] of 5 replications $(n=5)$. Means followed by the same letter for each respective day are not significantly different according to Duncan Multiple Range Test at $P<0.05$. Vertical bars indicate standard error of the means. 
In Vitro Bioassay of P. lilacinum and B. thuringiensis for Control of M. incognita

The infection of egg masses by $P$. lilacinum $A, P$. lilacinum $B$ and $P$. lilacinum $M$ was confirmed by observing the emerging mycelium from the surface of egg masses under a stereomicroscope $40 \times$ (Figs. 3a, 3b and 3c). On the first day, the rates of infection of egg masses ranging from 15 to $38 \%$ were recorded by $P$. lilacinum A, $P$. lilacinum $B$ and $P$. lilacinum $\mathrm{M}$ and then it increased to $90-95 \%$ on the third day and eventually achieved complete infection on the fifth day (Fig. 2b). There was no significant increase in percentage of infection of egg mass among $P$. lilacinum $\mathrm{A}, P$. lilacinum $\mathrm{B}$ and $P$. lilacinum $\mathrm{M}$ from the $3^{\text {rd }}$ day onwards. This was due to the presence of antimicrobial compound (as suggested by Orion, Kritzman, Meyer, Erbe, \& Chitwood, 2001) in gelatinous matrix (GM) of an egg mass can protect eggs from microbial infection (Kannan \& Veeravel, 2012). An effective parasite generally should be able to utilize GM as source of nutrient and then reproduce in it (Sharon et al, 2007). Since the mycelium was detected on the surface of GM in the present study, suggesting that $P$. lilacinum A and $P$. lilacinum B possess resistance towards antimicrobial compound present in the GM. This observation is in agreement with the studies on Meloidogyne spp. by Zaki \& Batti (1991) and Eapen et al (2005).
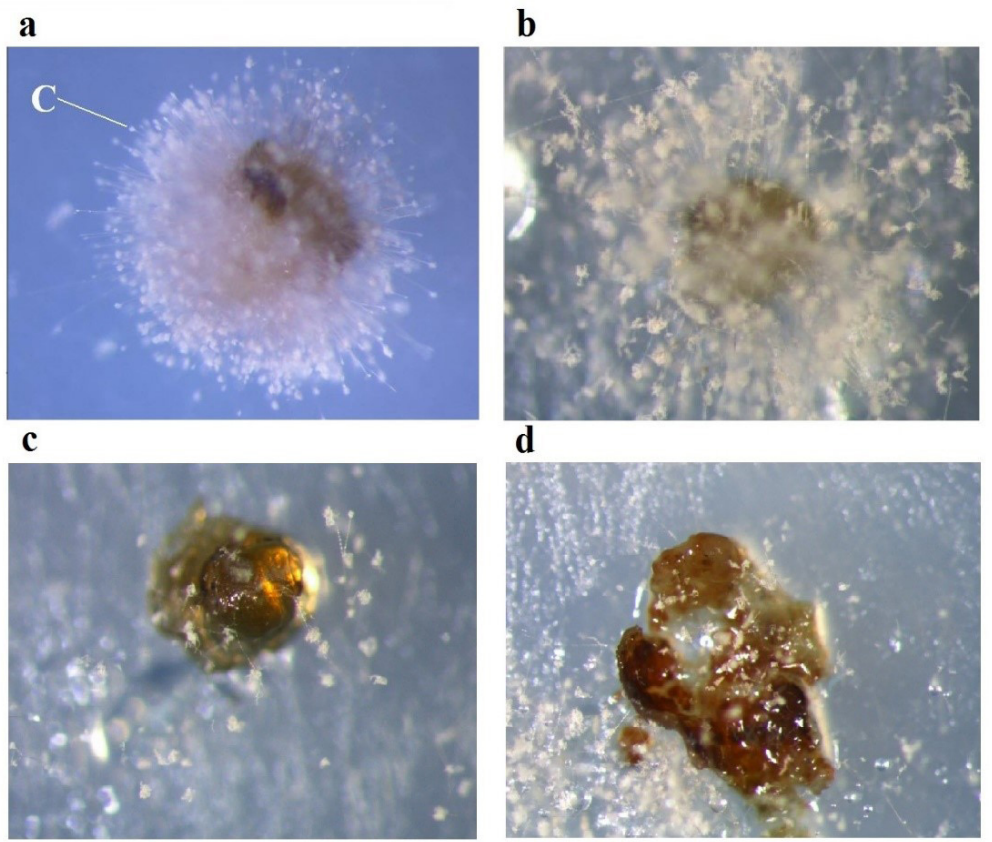

Fig. 3. Infection on Meloidogyne incognita female by PLM (a) \& PLA (b); hundreds of conidiosphores (C) radiating from the body surface. $c$ and $d$ Infection on egg mass by PLA; growing mycelium was detected on the surface of egg mass (c and d). Sign of infection was detected by observing the emerging hyphae from the surface of specimens (female or egg mass) under a stereo microscope at $40 \times$. 


\section{P. lilacinum parasitism on eggs of $M$. incognita}

The results demonstrated significant $(P<0.05)$ parasitic effect on $M$. incognita eggs with $78.5 \%, 73.4 \%$ and $66.0 \%$ parasitism for $P$. lilacinum A, P. lilacinum $\mathrm{M}$ and $P$. lilacinum B as compared with the control. However, it was noted that they did not differ significantly in percentage parasitism among themselves (Table 1). This result confirmed the observation made by Sun et al (2006) who reported a high in vitro parasitism rate of $P$. lilacinum strain YES-X-2-14 on M. hapla Chitwood eggs. In addition, another thirty $P$. lilacinum isolates of Sun et al (2006) were reported to parasitized $100 \%$ of $M$. hapla eggs. Al Kader (2008) stated that $77 \%$ infection of $M$. incognita eggs after 4 days of incubation.

Table 1. Impact of PL spore suspension ( $10^{5}$ spores $\left./ \mathrm{ml}\right)$ on parasitism of Meloidogyne incognita eggs, egg hatch inhibition and $\mathrm{J} 2$ mortality.

\begin{tabular}{|c|c|c|c|}
\hline Isolate & Parasitized egg (\%) & Hatch Inhibited egg (\%) & J2 Mortality (\%) \\
\hline PLA & $78.5 \pm 2.4^{\mathrm{a}}$ & $88.3 \pm 1.4^{\mathrm{a}}$ & $6.0 \% \pm 1.8^{\mathrm{a}}$ \\
\hline PLB & $66.0 \pm 5.2^{\mathrm{b}}$ & $88.2 \pm 1.7^{\mathrm{a}}$ & $5.5 \% \pm 0.8^{\mathrm{a}}$ \\
\hline PLM & $73.4 \pm 0.6^{\mathrm{ab}}$ & $89.4 \pm 1.0^{\mathrm{a}}$ & $5.7 \% \pm 1.0^{\mathrm{a}}$ \\
\hline Control & $0.0 \pm 0^{\mathrm{c}}$ & $25.9 \pm 3.12^{\mathrm{b}}$ & $2.3 \% \pm 0.8^{\mathrm{b}}$ \\
\hline
\end{tabular}

Each value (\%) represents the mean of four replications \pm standard error. Means within each column followed by the same letter are not significantly different according to Duncan Multiple Range Test at $\mathrm{P}<0.05$.

This study revealed that the eggs in their early stage with no sign of apparent juvenile shape being detected in the embryo were more susceptible to $P$. lilacinum $A$ and $P$. lilacinum $B$ infection than eggs at a later stage in which the embryo was already developed into an identifiable juvenile shape (Fig. 4b and 4c). In most cases, none of the juvenile 1 (J1) was detected in the infected eggs and the embryos seemed to be disintegrated (Fig. 4a, 4d and 4e), which reflected a parasitic effect of $P$. lilacinum on the developing embryos. In several eggs containing developing $\mathrm{J} 2$, emerging mycelium was also detected on the surface of these eggs and $\mathrm{J} 1$ appeared motionless. This has suggested that both P. lilacinum A and P. lilacinum B parasitized not only the immature eggs but also some mature eggs containing developing J1. Similar observations were made in the early studies on parasitized eggs of Meloidogyne spp. by Morgan-Jones et al. (1984), Irving \& Kerry (1986), Jatala (1986), Lopez-Llorca \& Duncan (1991), Holland et al (1999) and Eapen et al (2005). This attribute offers advantage in biological control since eggs of all Meloidogyne spp. are the major target of plant-parasitic fungus and can remain dormant in the soil for long periods of time.

Under microscopic observation, the hyphae of $P$. lilacinum form an extensive network were ramifying several eggs (Fig. 4f) but not growing on other adjacent eggs in the group. A simple, swollen, hyphal structure recognized as appressorium (Fig. 4f, AP) appeared at the end of hyphae is likely to be in contact with eggshells. Some incubated eggs appeared to be abnormal, deformed and shrunken may be due to the pressure exerted by the network of hyphae. The use of mechanical means to penetrate host was also reported by Holland et al (1999). 
In Vitro Bioassay of P. lilacinum and B. thuringiensis for Control of M. incognita

$\mathbf{a}$

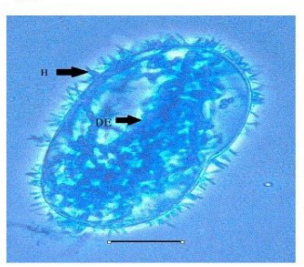

d b

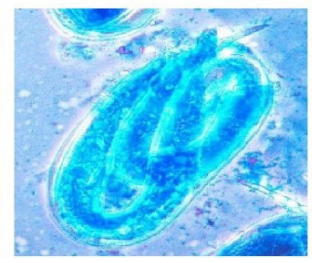

c

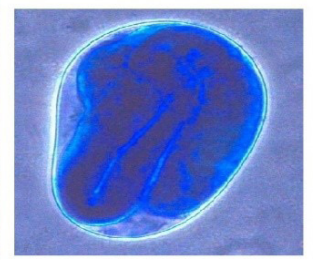

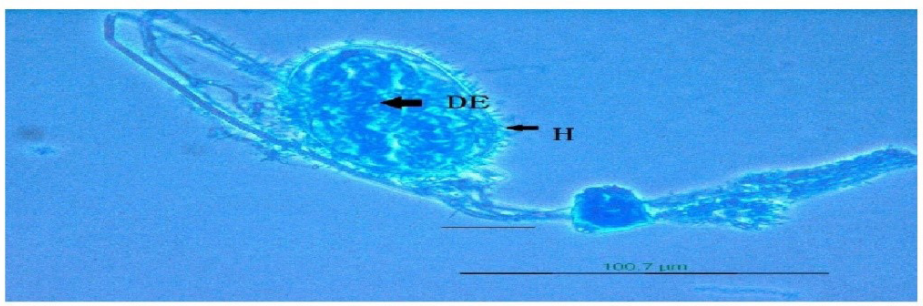

$\mathbf{e}$

$\mathbf{f}$
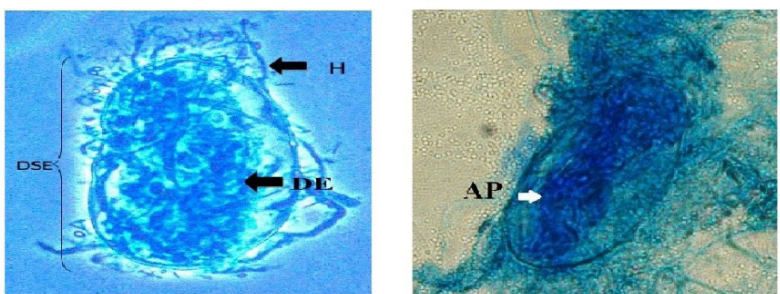

Fig. 4. Parasitism of Purpureocillium lilacinum on Meloidogyne incognita eggs. Hyphae $(\mathrm{H})$ emerged from a deformed shape egg (DSE) with disintegrated embryo (DE) of Meloidogyne incognita after 4 days of incubation. It also penetrated into the egg and consumed the egg content (400x magnification, photo $a, d$, e \& f). Photo b \& c: uninfected egg in control treatment. Photo f: Appresorium (AP) pressing on the egg. (' - ' is correspond to actual distance of $25 \mu \mathrm{m}$ ).

Once an egg is infected, the nutrient in the egg induces proliferation of hyphae on the egg, for enabling growth to adjacent eggs. In fact, eggshells of nematodes are the barriers to fungus infection (Morton, Hirsch, \& Kerry, 2004). They consist of three layers, namely a vitelline layer predominantly composed of proteins, a chitin-protein complex as the middle layer, which is responsible for egg structural strength (Gortari \& Hours, 2008) and lastly, an inner lipo-protein layer that protects egg from harmful chemical but loses its protective effect once the chitin layer is destroyed. According to Lopez-llorca, Olivares-Bernabeu, Salinas, Jansson, \& Kolattukudy, (2002), Lopez-llorca, MaciÁ-Civente, \& Jansson (2008), when a hypha encounters an egg surface, it forms appressoria (Fig. 4f) that subsequently adhere (using extracellular material on appressoria) to the egg for better binding of the fungus to the host (Lopez-llorca et al, 2008). From these appressoria, the fungus uses enzymatic and mechanical means to penetrate the host (Huang, Zhao, \& Zhang, 2004; Gortari \& Hours, 2008; Lopez-Llorca et al, 2008). The secretions of chitinase and proteases by $P$. lilacinum facilitate egg penetration by breaking down layers in eggshells (the barrier) 
so that a narrow infection peg can push through (Morton et al, 2004). The combined effect of chitinase and protease produced by $P$. lilacinum in degrading eggshell layers of $M$. javanica was reported by Khan et al (2004). The lipid layer disappeared while the chitin layer was much reduced after enzyme treatment. Besides, the involvement of serine protease, an extracellular protease penetrating the eggshell has been reported by Mérillon \& Ramawat (2012). This enzyme degrades vitellin component in immature eggs. They claimed that addition of chitin or vitellin to the fungal culture medium may induce proteolytic enzymes.

\section{Impact of $\boldsymbol{P}$. lilacinum on egg hatching of $\boldsymbol{M}$. incognita}

There are no significant differences in egg hatching inhibition rates (percentages) between all three $P$. lilacinum isolates $(P$. lilacinum $\mathrm{M}, P$. lilacinum $\mathrm{A}$ and $P$. lilacinum B) with $89.4 \pm 1.0 \%, 88.3 \pm 1.4 \%$ and $88.2 \pm 1.7 \%$, respectively, although significant $(\mathrm{P}<0.05)$ differences were observed among the treatment and the inoculated control (Table 1). Most eggs in the control treatment appeared empty, with the presence of many $\mathrm{J} 2$, suggesting hatching of eggs had occurred whereas eggs treated with spore suspension appeared to be shrunken, deformed and with multiple vacuoles. These studies corroborate the findings by Costa, Campos, Pfenning, \& Oliveira (2001) \& Sun et al (2006) who reported that culture filtrate of $P$. lilacinum grown in Czapek broth greatly reduced egg hatching of $M$. incognita and average $58 \%$ egg hatch inhibition of $M$. incognita for their $186 P$. lilacinum isolates and further confirm the higher rate of parasitized eggs and egg hatch inhibition of $M$. incognita. According to Mérillon \& Ramawat (2012), hatching of eggs containing mature juveniles appeared to be stimulated when incubated in culture filtrate of $P$. lilacinum but development of immature eggs appeared to be disrupted. Under some conditions, egg hatch percentage of plant-parasitic nematode was reported by Chen, Dickson, \& Mitchell (2000) to be higher in diluted culture filtrates of some fungi than in the media itself. They suggested that a hatching stimulant in the culture filtrate released by the fungi may gradually reduce the concentration of hatching inhibitor in the media by consuming the nutrient that contribute to a higher egg hatch percentage. This suggest that experimental conditions, fungal strains, culture media, and nematode species are among the different factors which may contribute to contradictory results.

\section{Impact of $P$. lilacinum on mortality of $2^{\text {nd }}$ stage juveniles (J2) of $M$. incognita}

In this study, no significant differences in mortality effect on $\mathrm{J} 2$ of $M$. incognita between all three $P$. lilacinum isolates $(P$. lilacinum $A, P$. lilacinum $B$ and $P$. lilacinum M) with low mortality of $6.0 \%, 5.5 \%$ and $5.7 \%$ respectively, although significant $(\mathrm{P}<0.05)$ differences were observed among the treatment and the inoculated control (2.3\%) (Table 1). The results of present study confirmed the findings of Sun et al (2006) who reported a low average J2 mortality percentage of $16 \%$ for their $186 P$. lilacinum isolates. Furthermore, it is in agreement with the reports by other researchers such as Jatala (1986), Bonant et al (1995), Singh \& Mathur (2010) that $P$. lilacinum primarily parasitized eggs but not juveniles of $M$. incognita. However, $P$. lilacinum 
In Vitro Bioassay of P. lilacinum and B. thuringiensis for Control of M. incognita

strain YES-X-2-14 was reported in exhibiting high in vitro nematicidal effect on J2 of Meloidogyne spp. (Sun et al, 2006). Similarly, Al Kader (2008) reported a high nematicidal effect of their $P$. lilacinum culture filtrate on J2 of $M$. incognita, with $99 \%$ of J2 immobilized after 2 days of treatment. It is suggested that different strain of $P$. lilacinum can exhibit different nematicidal effect on J2. Throughout the years, metabolites in culture filtrate of $P$. lilacinum have been detected and screened for paecilotoxin (Singh, Pandey, \& Goswami, 2013), acetic acid (Favre-Bonvin, Ponchet, Djian, Arpin, \& Pijarowski, 1991), and leucinostatins (Park et al, 2004). These metabolites may potentially result in death on $\mathrm{J} 2$ of $M$. incognita. The low mortality effect on $\mathrm{J} 2$ of $M$. incognita by spore suspension of the three $P$. lilacinum isolates (namely $P$. lilacinum $\mathrm{A}, P$. lilacinum $\mathrm{B}$ and $P$. lilacinum $\mathrm{M}$ ) in this study might be attributed to the absence of digestive enzyme secreted by the $P$. lilacinum or the amount of secreted enzyme was far below the threshold level to invade and penetrate the cuticle of J2 individuals. To infect $\mathrm{J} 2$ of $M$. incognita, $P$. lilacinum firstly needs to overcome the cuticle of nematode which is a non-cellular layer production of the hypodermis consisting of keratin, collagens and fibers (Huang et al, 2004). Once the cuticle is penetrated by fungal hyphae, the plant-parasitic nematodes $M$. incognita are then paralyzed, invaded and digested (Soares Sufiate, \& de Queiroz, 2018).

\section{Bacillus thuringiensis (Bt)'s parasporal crystal toxicity on $2^{\text {nd }}$ stage juveniles (J2) of M. incognita}

After 24 hours incubation, none of the treatments (3.12\%-50.00\% of harvested $B$. thuringiensis toxin, which includes cells, spores and crystals) affected the mobility of J2 (Table 2). B. thuringiensis crystal and endospores were ineffective in killing the J2 of $M$. incognita. The observation was continued for 48 hours and 77 hours, however, $B$. thuringiensis crystal proteins also did not demonstrate contact nematicidal effects on J2 of $M$. incognita for both periods of incubation. There was no significant difference on the percentage of paralyzed J2 among the treatments, which is in agreement with the finding of Devides \& Rehberger (1992) that purified $B$. thuringiensis toxin did not manifest contact nematicidal activity toward J2 of Meloidogyne spp. but was $100 \%$ active against the free-living nematode, Caenorhabditis elegans (Maupas) (Rhabditidae). There are several reasons that explain the ineffectiveness of harvested parasporal crystals of $B$. thuringiensis in killing J2 of Meloidogyne spp. First, phytonematodes including $M$. incognita have a modified feeding structure (known as stylet) which is too small to engulf material actively from soil as compared to bacteriophagous nematodes and substrate ingestor nematode. Therefore, the low mortality effect of $B$. thuringiensis on $\mathrm{J} 2$ of $M$. incognita may be due to the inability of its stylets to ingest $B$. thuringiensis toxin (crystal protein) as reported by Mozgovaya et al (2002) and Yu et al (2008). In fact, the presence of specific crystal protein genes in $B$. thuringiensis does not guarantee its toxicity because the genes may not be actively expressed or expressed in a concentration below the threshold level or under the control of a promoter which is not efficient (as cited by Salehi Jouzani, 
2008; Jansson et al, 1997; Ferrandis, Jua'rez-Pe'rez, Frutos, Bel, \& Ferré, 1999). Moreover, the toxicity of $B$. thuringiensis towards plant-parasitic nematodes can also be affected by solubilization and activation of crystal proteins before ingestion by pests (as cited by van Frankenhuyzen, 2009). Without an alkaline $\mathrm{pH}$, a crystal protein will not be able to dissolve in the midguts of nematodes, thus losing its toxicity effect on J2. Even though ingested crystal protein may show a certain level of toxicity, it can be proteolytically unstable after ingestion and thus not induce $\mathrm{J} 2$ mortality. Moreover, in the crystal proteins bioassay of Salehi Jouzani (2008), solubilization of $B$. thuringiensis crystal with $10 \mathrm{mmol} / \mathrm{L}$ of mercaptoethanol for $4 \mathrm{~h}$ at $37^{\circ} \mathrm{C}$ was included as one of the steps prior bioassay. In the present study, the technique of Carneiro et al (1998) was adopted without incorporating $B$. thuringiensis crystal solubilization as one of the steps before bioassay. It is speculated that the insolubility of $B$. thuringiensis crystal may also have contributed to its impact on $\mathrm{J} 2$ mortality in this study with $M$. incognita [although undiluted $B$. thuringiensis crystal ( $100 \%$ from crude harvest) was used in the bioassay]. Therefore, it is suggested that crystal protein solubilization should be included as an important step in all bioassays related to $B$. thuringiensis and $M$. incognita.

Table 2. Percentage of paralyzed J2 of Meloidogyne incognita after 24, 48 and 77 hours exposed to extract of spore-crystal mixtures of $B$. thuringiensis.

\begin{tabular}{|c|c|c|c|}
\hline $\mathbf{B T}$ & $\mathbf{2 4}$ Hours & $\mathbf{4 8}$ Hours & $\mathbf{7 7}$ Hours \\
\hline $\mathbf{5 0 \%}$ & $5.6 \pm 1.0$ & $13.0 \pm 2.6$ & $3.5 \pm 1.0$ \\
\hline $\mathbf{2 0} \%$ & $4.5 \pm 1.5$ & $6.0 \pm 1.4$ & $5.5 \pm 0.5$ \\
\hline $\mathbf{1 2 . 5} \%$ & $6.0 \pm 1.4$ & $5.6 \pm 1.7$ & $4.0 \pm 0.3$ \\
\hline $\mathbf{6 . 2 5} \%$ & $4.4 \pm 0.7$ & $4.4 \pm 1.5$ & $4.0 \pm 1.2$ \\
\hline $\mathbf{3 . 1 2} \%$ & $5.6 \pm 1.5$ & $4.0 \pm 1.4$ & $3.5 \pm 1.0$ \\
\hline Control & $3.6 \pm 1.2$ & $3.6 \pm 1.5$ & $4.0 \pm 0.0$ \\
\hline
\end{tabular}

Each value represents the mean (\%) of five replicates of paralyzed J2 \pm standard error, in the same column are not significantly different according to Duncan Multiple Range Test at $P<0.05, n=5$.

In contrast to the above finding, Prasad, Tilsk, \& Gollakota (1972) claimed that $B$. thuringiensis toxin at 10- fold dilution of fermentation beer, caused total mortality of J2 of M. incognita within 24 hours of incubation. Besides, Khan et al (2010) reported a $50 \%$ concentration of $B$. thuringiensis cell free culture filtrate significantly $(P<0.001)$ increased mortality of $\mathrm{J} 2$ in their in vitro studies. Studies by other researchers have revealed that the toxicity of $B$. thuringiensis towards nematodes is due to the extracellular $\beta$-exotoxins produced in the supernatant of the culture medium (Carneiro et al, 1998; Palma, Muñoz, Berry, Murillo, \& Caballero, 2014). Carneiro et al (1998) reported that sporulated cells and $\delta$-endotoxin of $B$. thuringiensis had no nematicidal effect on J2 of $M$. javanica. Surprisingly, Mohammed et al (2008) reported that the spore/crystal proteins of two $B$. thuringiensis isolates (Bt7N and BtDen) induced $100 \%$ mortality on J2 of $M$. incognita. Also, crystal protein toxin of $B$. thuringiensis strain YBT-021 was claimed manifesting toxicity effect to phytonematodes: $M$. 
In Vitro Bioassay of P. lilacinum and B. thuringiensis for Control of M. incognita

hapla, Pratylenchus scribneri Steiner in Sherbakoff \& Stanley (Pratylenchidae), Tylenchorhynchus sp. (Belonolaimidae), potato tuber nematode (Ditylenchus destructor Thorne (Anguinidae), and Aphelenchoides sp. (Aphelenchoididae) (Yu et al, 2008). Furthermore, Khyami-Horani et al (2003) revealed the toxicity of parasporal crystal protein of $B$. thuringiensis towards $3^{\text {rd }}$ stage larvae of Drosophila melanogaster Meigen (Diptera: Drosophilidae), J2 of $M$. javanica and M. incognita. When Meloidogyne spp. was treated with fluorescent labelled crystal protein toxin, the fluorescent signal accumulated in the intestinal tissue was detected (Yu et al, 2008). However, no study has been established in the entry mechanism of crystal protein into the intestinal tissue (Yu et al, 2008). Salehi Jouzani et al (2008) reported that newly hatched $\mathrm{J} 2$ were not affected by the parasporal crystal proteins of $B$. thuringiensis isolates YD5 and KON4 at $2 \times 10^{8} \mathrm{CFU} / \mathrm{mL}$ concentration after 24 hours of incubation. However, after 3-4 days of incubation, egg hatching inhibition was detected at $46 \%$ and $45 \%$ respectively, besides manifesting mortality effect on $M$. incognita at $77 \%$ and $81 \%$ respectively.

\section{CONCLUSION}

In the laboratory bioassay, $P$. lilacinum $A$ and $P$. lilacinum B were proven effective in parasitizing $M$. incognita females, eggs and $\mathrm{J} 2$ population as well as inhibiting egg hatch of $M$. incognita. Microscopic observation revealed that one of the antagonistic mechanisms of $P$. lilacinum is by proliferation of hyphae on the egg, which then penetrate the egg by mechanical and enzymatic means. Nevertheless, future study should be extended to screen and isolate each metabolite compound produced by $P$. lilacinum to further confirm the pathogenic effect of each respective metabolite towards different growth stage of $M$. incognita and other phytophagous nematodes (egg, juvenile or female).

On the other hand, $B$. thuringiensis crystal and endospores were found ineffective in killing the $\mathrm{J} 2$ of $M$. incognita in the laboratory bioassay. It was suspected that the feeding structure (stylet) of $M$. incognita is too small to ingest $B$. thuringiensis toxin or the specific crystal protein genes (Cry6 and Cry14) in B. thuringiensis might not be actively expressed or was expressed below the threshold level.

\section{ACKNOWLEDGEMENT}

Great appreciation is also extended to Malaysian Pepper Board for funding this project, Fund no: 6300301-11601. In addition, we appreciate the helpful comments provided by several reviewers of this manuscript.

\section{REFERENCES}

Al Kader, M.A.A. (2008). In vitro studies on nematode interactions with their antagonistic fungi in the rhizosphere of various plants. In PhD Thesis. Albert-Ludwigs Universität, Freiburg im Breisgau, Germany. 
Akyazi, F. \& Dickson, D.W. (2014). Pasteuria penetrans suppression of root-knot nematode Meloidogyne arenaria race 1 in vegetables. Turkish Journal of Entomology, 38(2), 173-180.

Barathi, S., Sangeetha, P., Karthick, C., Govindaraju, S., \& Indra Arulselvi, P. (2012). Diversity in protein profile of Bacillus thuringiensi strains isolated from varied soil environments. Journal of Pharmacy Research, 5(9), 4645-4647.

Bonants, P.J.M., Fitters, P.F.L., Thijs, H., Belder, E.D., Waalwijik, C., \& Henfling, J.W.D.M. (1995). A basic serine protease from Paecilomyces lilacinus with biological activity against Meloidogyne hapla eggs. Microbiology, 141, 775-784

Brand, D., Soccol, C.R., Sabu, A., \& Roussos, S. (2010). Production of fungal biological control agents through solid state fermentation: A case study on Paecilomyces lilacinus against root-knot nematodes. Micologia Aplicada International, 22(1), 31-48.

Brar, S.K., Verma, M., Tyagi, R.D., Valéro, J.R., \& Surampalli, R.Y. (2006). Efficient centrifugal recovery of Bacillus thuringiensis biopesticides from fermented wastewater and wastewater sludge. Water Research, 40(6), 1310-1320.

Cabanillas, E., Barker, K.R., \& Nelson, L.A. (1989). Growth of isolates of Paecilomyces lilacinus and their efficacy in biocontrol of Meloidogyne incognita on tomato. Journal of Nematology, 21, 164-172.

Carneiro, R.M.D.G., Souza, I.S.D., \& Belarmino, L.C. (1998). Nematicidal activity of Bacillus spp. strains on juveniles of Meloidogyne javanica. Nematologia Brasileira, 22, 12-19.

Chen, S.Y., Dickson, D.W., \& Mitchell, D.J. (2000). Viability of Heterodera glycines exposed to fungal filtrates. Journal of Nematology, 32, 190-197.

Costa, M.J.N., Campos, V.P., Pfenning, L.H., \& Oliveira, D.F. (2001). Toxicidade de filtrados fúngicos a Meloidogyne incognita. Fitopatologia Brasileira, 26(4), 749-755.

Favre-Bonvin, J., Ponchet, M., Djian, C., Arpin, N., \& Pijarowski, L. (1991). Acetic acid: a selective nematicidal metabolite from culture filtrates of Paecilomyces lilacinus (Thom) Samson and Trichoderma longibrachiatum Rifai. Nematologica, 37(1-4), 101-112.

Devidas, P. \& Rehberger, L.A. (1992). The effects of exotoxin (Thuringiensin) from Bacillus thuringiensis on Meloidogyne incognita and Caenorhabditis elegans. Plant and Soil, 145, 115-120.

Dong, L.Q. \& Zhang, K.Q. (2006). Microbial control of plant-parasitic nematodes: a five-party interaction. Plant and Soil, 288(1-2), 31-45.

Dube, B. \& Smart, G.C.Jr. (1987). Biological control of Meloidogyne incognita by Paecilomyces lilacinus and Pasteuria penetrans. Journal of Nematology, 19, 222-227.

Eapen, S.J., Beena, B. \& Ramana, K.V. (2005). Tropical soil microflora of spice-based cropping systems as potential antagonists of root-knot nematodes. Journal of Invertebrate Pathology, 88(3), 218-225.

El-Nagdi, W.M.A. \& Youssef, M.M.A. (2004). Soaking faba bean seed in some bio-agents as prophylactic treatment for controlling Meloidogyne incognita root-knot nematode infection. Journal of Pest Science, 77(2), 75-78.

Eng, L. (2001). Biological control of root-knot nematodes (Meloidogyne species) on black pepper (Piper nigrum L.) in Sarawak. In PhD Thesis. University of Reading, United Kingdom.

Ferrandis, M.D., Jua'rez-Pe'rez, V.M., Frutos, R., Bel, Y. \& Ferré, J. (1999). Distribution of cryl, cryll and cryV genes within Bacillus thuringiensis isolates from Spain. Systematic and Applied Microbiology, 22, 179-185.

Freitas, L.G., Ferraz, S., \& Muchovej, J.J. (1995). Effectiveness of different isolates of Paecilomyces lilacinus and an isolate of Cylindrocarpon destructans on the control of Meloidogyne javanica. Nematropica, 25, 109-115.

Glass, N.L. \& Donaldson, G.C. (1995). Development of primers sedesigned for use with the PCR to amplify conserved genes from filamentous Ascomycetes. Applied and Environmental Microbiology, $61,1323-1330$.

Gortari, M.C. \& Hours, R.A. (2008). Fungal chitinases and their biological role in the antagonism onto nematode eggs. A review. Mycological Progress, 7(4), 221-238. 
In Vitro Bioassay of P. lilacinum and B. thuringiensis for Control of M. incognita

Gowen, S.R. (1997). Chemical control of nematodes: efficiency and side-effects. Retrieved from http:// www.fao.org/3/v9978e08.htm.

Holland, R.J., Williams, K.L. \& Khan, A. (1999). Infection of Meloidogyne javanica by Paecilomyces lilacinus. Nematology, 2, 131-139.

Huang, X., Zhao, N., \& Zhang, K. (2004). Extracellular enzymes serving as virulence factors in nematophagous fungi involved in infection of the host. Research in Microbiology, 155(10), 811-816.

Inglis, P.W. \& Tigano, M.S. (2006). Identification and taxonomy of some entomopathogenic Paecilomyces spp. (Ascomycota) isolates using rDNA-ITS Sequences. Genetics and Molecular Biology, 29, 132-136.

Irving, F. \& Kerry, B.R. (1986). Variation between strains of the Nematophagous Fungus, Verticillium Chlamydosporium Goddard. li. factors affecting parasitism of cyst nematode eggs. Nematologica, 32(4), 474-485.

Jatala, P. (1986). Biological control of plant parasitic nematodes. Annual Review of Phytopathology, 24, 453-489.

Jansson, H.-B., Tunlid, A., \& Nordbring-Hertz, B. (1997). Nematodes. In T., Anke (Ed.). Fungal Biotechnology (pp. 38-48). Weinheim, Germany: Chapman and Hall.

Kannan, R. \& Veeravel, R. (2012). Effect of different dose and application methods of Paecilomyces lilacinus (Thom.) Samson against root knot nematode, Meloidogyne incognita (Kofoid and White) Chitwood in okra. Journal of Agricultural Science, 4(11), 119-127.

Khan, A., Williams, K.L., \& Nevalainen, H.K.M. (2004). Effects of Paecilomyces lilacinus protease and chitinase on the eggshell structures and hatching of Meloidogyne javanica juveniles. Biological Control, 31(3), 346-352.

Khan, A., Williams, K.L. \& Nevalainen, H.K.M. (2006a). Control of plant-parasitic nematodes by Paecilomyces lilacinus and Monacrosporium lysipagum in pot trials. Biocontrol, 51(5), 643-658.

Khan, A., Williams, K.L. \& Nevalainen, H.K.M. (2006b). Infection of plant-parasitic nematodes by Paecilomyces lilacinus and Monacrosporium lysipagum. Biocontrol, 51(5), 659-678.

Khan, M.Q., Abbasi, M.W., Zaki, M.J., \& Khan, S.A. (2010). Evaluation of Bacillus thuringiensis isolates against root-knot nematodes following seed application in okra and mungbean. Pakistan Journal of Botany, 42, 2903-2010.

Khyami-Horani, H., Hajaij, M., \& Charles, J.F. (2003). Characterization of Bacillus thuringiensis ser. jordanica (Serotype H71), a novel serovariety isolated in Jordan. Current Microbiology, 47(1), 26-31.

Kiewnick, S. \& Sikora, R.A. (2006). Biological control of the root-knot nematode Meloidogyne incognita by Paecilomyces lilacinus strain 251. Biological Control, 38(2), 179-187.

Kueh, T.K. \& Teo, C.H. (1978). Chemical control of root-knot nematodes in Piper nigrum. The Planter, $54,237-245$.

Kueh, T.K. (1986). Pests and diseases of black pepper (Piper nigrum) - a review Pepper (Piper nigrum L.) in Malaysia. In Proceedings of the National Conference on Pepper in Malaysia (pp. 115-133). Malaysia: Malaysia Pepper Board.

Kueh, T.K. (1990). Major diseases of black pepper and their management. The Planter, 66: 59-69.

Kueh, T.K. \& Sim, S.L. (1992). Slow decline of black pepper caused by root knot nematodes. In P., Wahid, D., Sitepu, S., Deciyanto \& U., Suparman (Ed.). Proceedings International Workshop on Black Pepper Disease (pp. 198-206). Bogors, Indonesia: Research Institute for Spice and Medicinal Crops Press.

Leong, C.T.S. (1986). Pepper nematodes. In Annual Report for the Year 1984 (pp. 74-78). Malaysia: Department of Agriculture.

Li, T.M. (1999). Introduction. In T.M., Li (Ed.). Transforming the Indonesian Uplands (pp. 8-24). Amsterdam, Harwood Academic Publishers.

Lopez-Llorca, L.V. \& Duncan, G.H. (1991). Effects of fungal parasites on cereal cyst nematode (Heterodera avenae Woll.) from naturally infested soil-a scanning electron microscopy study. Canadian Journal of Microbiology, 37(3), 218-225 
LEONG, S.S., LEONG, S.C.T., PAU, C.G., BEATTIE, G.A.C.

Lopez-llorca, L.V., MaciÁ-Civente, J.G., \& Jansson, H.-B. (2008). Mode of action and interactions of nematophagous fungi. In A., Ciancio \& K.G., Mukerji (Eds.). Integrated Management and Biocontrol of Vegetable and Grain Crops Nematodes (pp. 51-76). Netherlands: Springer.

Lopez-llorca, L.V., Olivares-Bernabeu, C., Salinas, J., Jansson, H.-B., \& Kolattukudy, P.E. (2002). Pre-penetration events in fungal parasitism of nematode eggs. Mycological Research, 106(4), 499-506.

Luangsa-Ard J., Houbraken J., van Doorn T., Hong S.B., Borman A.M., Hywel-Jones N.L., \& Samson R.A.(2011). Purpureocillium, a new genus for the medically important Paecilomyces lilacinus. FEMS Microbiol Lett. 321:141-149.

Mérillon, J.M. \& Ramawat, K.G. (2012). Plant defence: biological control. New York: Springer.

Ministry of Plantation Industries and Commodities (MPIC). (2013). Statistics of Commodities 2013. Malaysia: Ministry of Plantation Industries and Commodities (MPIC) Press.

Mohammed, S.H., Saedy, A.E.M., Enan, M.R., Ibrahim, N.E., Ghareeb, A., \& Moustafa, S.A. (2008). Biocontrol efficiency of Bacillus thuringiensis toxins against root-knot nematode, Meloidogyne incognita. Journal of Cell Molecular Biology, 7, 57-66.

Morgan-Jones, G., White, J.F., \& Rodriguez-Kabana, R. (1984). Phytonematode pathology: Ultrastructural studies II. Parasitism of Meloidogyne arenaria eggs and larvae by Paecilomyces lilacinus. Nematropica, 14, 57-71.

Morton, O., Hirsch, P., \& Kerry, B. (2004). Infection of plant-parasitic nematodes by nematophagous fungi - a review of the application of molecular biology to understand infection processes and to improve biological control. Nematology, 6(2), 161-170.

Mozgovaya, I.N., Byzov, B.A., Ryabchenko, N.F., Romanenko, N.D., \& Zvyagintsev, D.G. (2002). Nematicidal effects of the entomopathogenic bacteria Bacillus thuringiensis in soil. Pedobiologia, 46(6), 558-572.

Mukhtar, T. \& Pervaz, I. (2003). In vitro evaluation of ovicidal and larvicidal effects of culture filtrate of Verticillium chlamydosporium against Meloidogyne javanica. International Journal of Agriculture and Biology, 4, 576-579.

Nitao, K.N., Meyer, S.L.F., \& Chitwood, D.J. (1999). In vitro assays of Meloidogyne incognita and Heterodera glycines for detection of nematode-antagonistic fungal compounds. Journal of Nematology, 1, 172-183.

Orion, D., Kritzman, G., Meyer, S.L.F., Erbe, E.F., \& Chitwood, D.J. (2001). A role of the gelatinous matrix in the resistance of root-knot nematode (Meloidogyne spp.) eggs to microorganisms. Journal of Nematology, 33, 203-207.

Oclarit, E. \& Cumagun, C. (2009). Evaluation of Efficacy of Paecilomyceslilacinus as biological control agent of Meloidogyne incognita attacking tomato. Journal of Plant Protection Research, 49(4), 337-340.

Osman, H.A., Ameen, H.H., Mohamed, M., El-Mohamedy, R., \& Elkelany, U.S. (2018). Field control of Meloidogyne incognita and root rot disease infecting eggplant using nematicide, fertilizers, and microbial agents. Egyptian Journal of Biological Pest Control, 28(1),1-6.

Palma, L., Muñoz, D., Berry, C., Murillo, J., \& Caballero, P. (2014). Bacillus thuringiensis toxins: an overview of their biocidal activity. Toxins, 6(12), 3296-3325

Park, J.-O., Hargreaves, J.R., McConville, E.J., Stirling, G.R., Ghisalberti, E.L., \& Sivasithamparam, K. (2004). Production of leucinostatins and nematicidal activity of Australian isolates of Paecilomyces lilacinus (Thom) Samson. Letters in Applied Microbiology, 38(4), 271-276.

Prasad, S.S.V., Tilsk, K.V.R., \& Gollakota, K.G. (1972). Role of Bacillus thuringiensis var. thuringiensis on the larval survivability and egg hatching of Meloidogyne spp. The causative agent of root-knot disease. Journal of Invertebrate Pathology, 20, 377-378.

Ramana, K.V. \& Eapen, S.J. (2000). Nematode induced diseases of black pepper. In P., Ravindran (Ed.). Black Pepper Piper nigrum (pp. 269-295). Malaysia: Harwood academic publishers. 
In Vitro Bioassay of P. lilacinum and B. thuringiensis for Control of M. incognita

Salehi Jouzani, G., Seifinejad, A., Saeedizadeh, A., Nazarian, A., Yousefloo, M., Soheilivand, S., Mousivand, M., Jahangiri, R., Yazdani, M., Amiri, R.M., \& Akbari, S. (2008). Molecular detection of nematicidal crystalliferous Bacillus thuringiensis strains of Iran and evaluation of their toxicity on free-living and plant-parasitic nematodes. Canadian journal of Microbiology, 54, 812-822.

Sharif, F.A. \& Alaeddinoğlu, N.G. (1998). A rapid and simple method for staining of the crystal protein of Bacillus thuringiensis. Journal of Industrial Microbiology, 3, 227-229.

Sharon, E., Chet, I., Viterbo, A., Bar-Eyal, M., Nagan, H., Samuels, G.J., \& Spiegel, Y. (2007). Parasitism of Trichoderma on Meloidogyne javanica and role of the gelatinous matrix. European Journal of Plant Pathology, 118(3), 247-258.

Siddiqui, Z.A. \& Mahmood, I. (1994). Culture of Paecilomyces lilacinus on leaf extracts and leaf residues for nematode control. Bioresource Technology, 49, 187-189.

Singh, S \& Mathur, N. (2010). In vitro studies of antagonistic fungi against the root-knot nematode, Meloidogyne incognita. Biocontrol Science and Technology, 20, 275-282.

Singh, S., Pandey, R.K., \& Goswami, B.K. (2013). Bio-control activity of Purpureocillium lilacinum strains in managing root-knot disease of tomato caused by Meloidogyne incognita. Biocontrol Science and Technology, 23(12), 1469-1489.

Soares, F.E. de F., Sufiate, B.L., \& de Queiroz, J.H. (2018). Nematophagous fungi: Far beyond the endoparasite, predator and ovicidal groups. Agriculture and Natural Resources, 52(1), 1-8.

Sun, M.H., Gao, L., Shi, Y.X., Li, B.J., \& Liu, X.Z. (2006). Fungi and actinomycetes associated with Meloidogyne spp. eggs and females in China and their biocontrol potential. Journal of Invertebrate Pathology, 93(1), 22-28.

Thomas P., Sekhar, A.C., Upreti, R., Mujawar, M.M., \& Pasha,S.S. (2015). Optimization of single plate-serial dilution spotting (SP-SDS) with sample anchoring as an assured method for bacterial and yeast cfu enumeration and single colony isolation from diverse samples. Biotechnology Reports, 8 , 45-55.

Timper, P. (2014). Conserving and enhancing biological control of nematodes. Journal of Nematology, 46(2), 75-89.

Van Frankenhuyzen, K. (2009). Insecticidal activity of Bacillus thuringiensis crystal proteins. Journal of Invertebrate Pathology, 101(1), 1-16.

Xavier, R., Reena Josephine, C.M., \& Sreeramanan, S. (2007). Environmental distribution and diversity of insecticidal proteins of Bacillus thuringiensis Berliner. Malaysian Journal of Microbiology, 3, 1-6.

Zi-Quan, Y., Qian-Lan, W., Bin, L., Xue, Z., Zi-Niu, Y., \& Ming, S. (2008). Bacillus thuringiensis crystal protein toxicity against plant-parasitic nematodes. Chinese Journal of Agricultural Biotechnology, $5(1), 13-17$.

Yu, Z.Q., Wang, Q.L., Liu, B., Zou, X., Yu, Z.N., \& Sun, M. (2008). Bacillus thuringiensis crystal protein toxicity against plant-parasitic nematodes. Chinese Journal of Agricultural Biotechnology, 5, 13-17.

Zaki, F.A. \& Bhatti, D.S. (1991). Effect of culture media on sporulation of Paecilomycels lilacinus and its efficacy against Meloidogyne javanica in tomato. Nematologia Mediterranea, 19, 211-212. 